\title{
Peeking into students' mental imagery: the Report Aloud technique in Science Education research
}

\author{
Espiando suas imagens mentais: a técnica Report Aloud \\ na pesquisa em Ensino de Ciências
}

\author{
Robson Trevisan ${ }^{1}$ \\ https://orcid.org/0000-0001-9107-6315 \\ Agostinho Serrano ${ }^{1}$ \\ https://orcid.org/0000-0002-7868-1526 \\ Jeferson Wolff ${ }^{2}$ \\ https://orcid.org/0000-0002-3137-5839 \\ Adriana Ramos ${ }^{3}$ \\ https://orcid.org/0000-0002-4832-7251
}

\begin{abstract}
The goal of this article is to present a qualitative methodological proposal for researching Science teaching. We produced the article based on premises of the Think-Aloud method and Depictive Gesture Analysis. Here, we report on the structuring of the Think-Aloud technique, a novelty within the scope of research in education and applications in the teaching of Chemistry and Physics. The main advantages of this approach is its potential to establish a link between verbal and body language, which is produced by the participants during data production through the dialogues proposed within this research. Therefore, the procedures in the study allow for a more accurate analysis because of the pieces of evidence obtained from speaking, writing, and the gestures for the identification of mental images formed by the students about the scientific concepts they have studied.
\end{abstract}

Keywords: Science teaching. Research methods. Depictive gesture analysis. Think-aloud technique. Think-aloud method.

Resumo: Neste artigo apresentamos uma proposta metodológica qualitativa para a investigação em ensino de Ciências, construída a partir das premissas do método Think Aloud e da Análise Gestual Descritiva. Descrevemos, portanto, a estruturação da técnica Report Aloud, inédita no âmbito da pesquisa em ensino, e suas aplicações recentes em trabalhos inclinados ao ensino de química e de física. As principais vantagens deste delineamento metodológico são as suas potencialidades ao estabelecer um enlace entre a linguagem verbal e a gestual, manifestadas pelos sujeitos da pesquisa ao longo do processo de produção de dados, ocorrido por meio de diálogos propostos pelas investigações dentro desse universo de pesquisa. Desta forma, é possível realizar uma análise com maior acuracidade, obtendo evidências oriundas da fala, da escrita e dos gestos para a identificação de imagens mentais dos estudantes acerca de determinados conceitos científicos estudados.

Palavras-chave: Ensino de ciências. Metodologia da pesquisa. Pesquisa qualitativa. Análise gestual descritiva. Método think aloud. Técnica report aloud.

\footnotetext{
${ }^{1}$ Universidade Luterana do Brasil (ULBRA), Programa de Pós-Graduação em Ensino de Ciências e Matemática, Canoas, RS, Brasil. E-mail: robson.trevisan@rede.ulbra.br.

${ }^{2}$ Instituto Federal Sul-Rio-Grandense (IFSUL), Charqueadas, RS, Brasil.

${ }^{3}$ Instituto Federal de Educação, Ciência e Tecnologia do Rio Grande do Sul (IFRS), Porto Alegre, RS, Brasil.
} 


\section{Introduction}

The teaching of science in Brazil has gained an important place in the curricula of basic education. According to Nardi and Almeida (2004), the growing disposition in the last decades of the subjects of Chemistry, Biology, and Physics in school studies is related to the technological advances of society. The contributions of this scientific development reflect the need to expand informal discussion spaces. Without momentarily entering into merits of the way science is instructed, its presence in the educational system is notorious.

In this regard, the research carried out by Nardi (2014) shows us an increase in the number of researchers in Brazil working on the field called Science Teaching or also known as Science Education. The studies indicate, in addition to the numbers of productions in the form of a thesis, dissertations, and scientific articles, the various journals currently being published in the country and the events carried out with rigorous regularity, an important evidence of the consolidation of studies and research in science education.

When we refer to research in science education, we take as a perspective the view adopted by Moreira (2004), which points out that one of the main objective of science teaching research is the constant search to answer questions and concerns related to the axes of teaching, learning, curriculum and educational context in sciences, also encompassing investigations regarding the performance and teacher training, on a harmonious and consistent framework in epistemological, theoretical and methodological scope.

Science education is indeed an established scientific research field; however, Nardi and Almeida (2007) raise the question of methodological divergences of the published researches, showing that there is no consensus among the researchers of the field regarding the nature of what and how to research. Under this background, we will present a qualitative methodological proposal for research in science education, built through the connection between the Think Aloud protocol and Depictive Gesture Analysis.

The Report Aloud technique uses an adaptation of the "Think Aloud" protocol (VAN-SOMEREN; BARNARD; SANDBERG, 1994) used to conduct an interview based on questions of an instrument for data production, answered by the research subject. In this process, the student reports to the interviewer his/her thinking process while answering the questions, or "thinking out loud." In the modified technique Report Aloud, the student solves the questions first and only then, when finalizing them, reports / remembers his/her thought process.

The whole dialogue is recorded in audio and video so that Depictive Gesture Analysis can be performed, based on the line of work of Monaghan and Clement (1999) and Stephens Clement (2010), this analysis consists in the use of hand movements as an indicator of the use of dynamic images of mental simulations by students during the problem-solving task. Given this, it is believed in the possibility of obtaining the student's implicit knowledge inherent in their internal visualizations (mental simulation of reasoning). Therefore, the gestures can transmit information that otherwise is almost impossible to communicate whenever there is a difficulty of verbal expression.

We will present in this article three pioneering investigations in the use of this methodology throughout the proposed investigative processes. Two works are inclined to Physics teaching, Wolff (2015), in which deals with mechanical collisions, and Trevisan (2016), who 
realizes a study on the wave-particle duality, a work directed to Chemistry teaching, Ramos (2015), in which addresses molecular modeling.

From the results presented in the mentioned researches, we will try to answer the following questions that led us to this work: How can the Report Aloud technique, used in the conduction of a semi-structured interview, promote the identification of mental images of students? And what are the potential of Depictive Gesture Analysis in qualitative research in Science Teaching?

By answering those questions, we aim to disclose some possibilities offered by this method - that is to peek into the internal, imagistic speech and the external verbal speech that, analyzed together, can reveal much of the students' cognitive processes when solving a scientific problem.

\section{Report Aloud technique: facilitating dialogue}

In several research contexts in science teaching, the interaction with students is a part of the methodological process to produce data and evidence, leading to answers to the initial concerns of the research. At the moment of the interviews, whether they are semi-structured or not, the researcher and the participant subject openly dialog, in which the researcher seeks to obtain more information about the subject's opinion/posture in relation to a certain subject that has been investigated.

With the objective of extracting as much information as possible about the cognitive processes performed by the students, when they are encouraged to express themselves on certain contents of knowledge, we propose a method, Report Aloud, to conduct semi-structured interviews.

The Report Aloud technique is an adaptation of the Think Aloud protocol (VANSOMEREN; BARNARD; SANDBERG, 1994). The difference between the methods is that in Think Aloud, the interviewer and the interviewee maintain a constant dialogue about what the interviewee is thinking about during the execution of a task, that is, while the student answers the questionnaire, he thinks aloud. On the other hand, in Report Aloud, the student reports to the interviewer his/her thought process while answering the questions, that is, the student solves the questions and only then when he/she finishes them, reports his/her thought process.

The option to fit the original Think Aloud protocol was taken considering the main advantages and disadvantages of each method. We believe that the main advantage of the original technique is that the students solve the problem and at the same time explain their reasoning to the interviewer - this process is able to fully reveal what the student's reasoning process is in real time, the disadvantage is that, in this way, the technique itself causes a change in the process, since the student may feel pressured to respond quickly and correctly with the presence of another person who observes it throughout the resolutions.

On the other hand, the report aloud technique has a negative aspect in which the interviewer does not know, with absolute certainty, if the steps reported (or remembered) by the students were the same ones used to solve the problem (which, in general, takes place sometime before the interview); however, the process of solving the problems proposed is not disturbed by the technique and occurs more naturally under similar conditions when the student 
solves a problem on his own. Analysing the work of Ramos (2015), Wolff (2015) and Trevisan (2016), who used the report aloud, it was found that even after a few days spread between problem-solving and interviewing with their answers, the student could remember the most important details that led to the answers, reporting them to the interviewer with great confidence that what he was reporting was what happened during the resolution of the problem.

At this point, the interviewer seeks to disclose all the paths used by the subject to construct his response, thus seeking through the verbal and gestural discourse to identify the mental images of the students throughout their process of reasoning and externalization ideas. According to the studies of contemporary cognitive psychology, individuals do not directly appropriate the external environment, they create mental representations, their own ways of representing the external world internally (MOREIRA, 1996). In this way, a representation, both internal and external, is any notation, sign or set of symbols that represents some aspect of the external world or the imagination (EISENCK; KEANE, 1994). The existence of mental images is not neglected by researchers, and although they have been neglected by cognitive psychologists several times, they seem to play a key role in scientific development (ANDERSON, 1978).

In this methodological proposal, the aim is to identify mental images used by students to answer some questions before and after an instruction mediated by some activity. Therefore, we consider that such images are expressed from access to visual information stored in the student's memory. For this, we assume the conception about mental images presented by Otero (2004), in which he estimates the images as analogical representations with structural similarity to what they represent, and not mere subjective experiences. These images can be generated by viewing some object or situation, even if briefly, or, in most cases, the images are generated based on a set of information stored in memory.

The entire interview conducted by using the Report Aloud technique is recorded in audio and video so that proper transcription is performed along with the identification of possible depictive gestures performed by the students throughout their explanations. The observed gestures will serve as indicators for Gesture Analysis (MONAGHAN; CLEMENT, 1999; STEPHENS; CLEMENT, 2010) which will be commented below.

Some important points that the interviewer has to keep in mind during the interview:

Starting the interview itself, it is best to explain the think aloud protocol, in which the objective of the interview is to understand the thinking process of the interviewed. One general example can be offered to the interviewed, as how someone can plan ahead his lunchtime by mentally scheduling what he is going to do in the next few hours before lunch, after staring at a clock and imagining going to the place where he is going to have a meal, describing it in detail.

The first question of the interviewer should be in the line of inquiring what was the very first thought the interviewed had when he read the problem in the test he answered. The interviewer should then ask as many details as he can ask about the nature of the object/idea imagined, like color, shape, size, and more importantly: where this image come from (a book, a teacher, a software, an experiment, a childhood experience, etc).

During the interview, the posture should be of offering none help - at best as little as possible just to keep the interview fluid - to compliment the student's explanation.

The interview main purpose is to identify the mental images used by the student when he answers the test, but further details or modifications of problems solved can also be 
included (what if instead of a light we used a laser? What comes to your mind as I ask you this? Any images at all?).

Student gestures must be recorded all the time and the camera must be focusing on his hands and face. Preferably also the interviewer's hands and face, but this is not mandatory.

\section{Depictive Gesture Analysis}

The methodology of gestural analysis adopted by this research is based on the line of work of Monaghan and Clement (1999), and Stephens and Clement (2010). These works suggest the establishment of a relation between mental images present in the student's cognitive structure and gestures made by the student. By treating the close relationship between mental images and gestures of the students, the works consider these as concrete pieces of evidence of the cognitive processes developed by the subjects when asked about certain situations or problems.

Monaghan and Clement (1999) carried out a study on the usage of a computer simulation in the teaching concepts about relative movement with high school students in North America, trying to verify if the simulation can help to improve the understanding of the concepts. In their qualitative methodological basis, the authors conducted interviews with three students after the activities were carried out, aiming to assess the effectiveness of the computational simulation as a pedagogical tool. Monaghan and Clement (1999) observed that students combined verbal statements with depictive gestures related to their explanations, suggesting an attempt to visualize the problem.

This verbal-gestural relation can be observed in the following excerpt

[Student:] [...] I saw the black car moving faster (moves right hand quickly to the left) than the white car and the white car was moving backwards as if the plane (points to computer screen) was going past it. And the black car is moved faster as if the plane was going towards it (moves right hand to the left). (MONAGHAN; CLEMENT, 1999, p. 929, emphasis added by us).

Thus, the authors used as one of the indicators for the analysis the hand movements suggesting that the students were using dynamic images of mental simulation during the task of solving relative motion problems. Therefore, there is, in fact, the possibility of obtaining implicit knowledge of the student inherent in his internal visualization (mental simulation of reasoning), after hyper cultural mediation (in the form of computer simulation) through his gestural externalization.

The interpretation of the gestures may provide information that is not identified only through speech. However, we reinforce the importance of verbal and gestural association in the transmission of information without such resources being used during the explanation to be redundant. That is, the information transmitted in a gesture is related to what is transmitted verbally, without both necessarily being the same transmitted information. Therefore, the gestures can help the transmission of information whenever there is a difficulty of verbal expression. 
Thus, it is possible to identify patterns of gestures and relate them to the implicit knowledge existing in the students' cognitive structure. Here, we consider gestures as their own language and not as a complement to verbal language, and the union of these two resources is considered an important tool in the identification of concepts acquired and/or modified after the proposed activities.

Stephens and Clement (2010) conducted a study in which they sought the identification of reasoning and mental images of high school students about basic concepts of force and motion present in gravitational theory. The authors describe the gestural analysis together with the verbal analysis as a methodology used to identify evidence of the uses of three rationales categorized by the study, named analogies, extreme cases, and imaginary experiments.

The data were produced through audio and video recordings performed during the Physics subject. The cameras were arranged in the classroom so that all students could be observed. In this way, all teacher instructions and all student participation during classes were recorded.

Following the movement of analysis, the researchers coded the videos from the depictive images, knowing that the gestures seemed to represent an object, a place or an imaginary action. Thus, gestures were taken as an indication that a mental image is being used to express ideas about a subject. Stephens and Clement (2010) classified three categories: the gestures obtained, which represent a form and indicate mental images considered as static, the category of gestures that represent the movement of an object and indicate dynamic mental images, and the category of gestures that indicate the action of a force. We emphasize that this classification adopted by the authors follow their investigative objectives, other forms of organization could be attributed to the same sets of gestures, in the following section we present other examples of classification and gestural analysis in studies inclined to the of physics and chemistry teaching in undergraduate courses. strength.

Figure 1 presents the example prepared by the authors for an indicative gesture of

Figure 1 - Depictive gestures indicative-strength. The Earth makes a greater pull on you
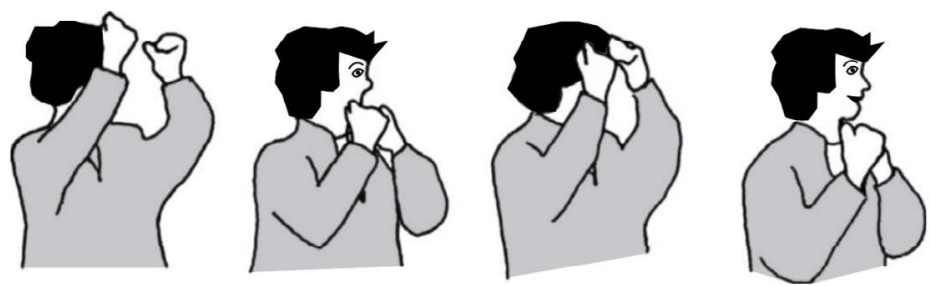

Source: Adapted from Stephens and Clement (2010, p. 6).

In this sequence of images, the subject represents with his hands the attraction felt by the influence of terrestrial gravitational field. Through the images obtained during the recordings, Stephens and Clement (2010) present other depictive gestures used in their analysis as indicators of mental images, as it is shown in figure 2 . 
Figure 2 - The book would simply fly into space

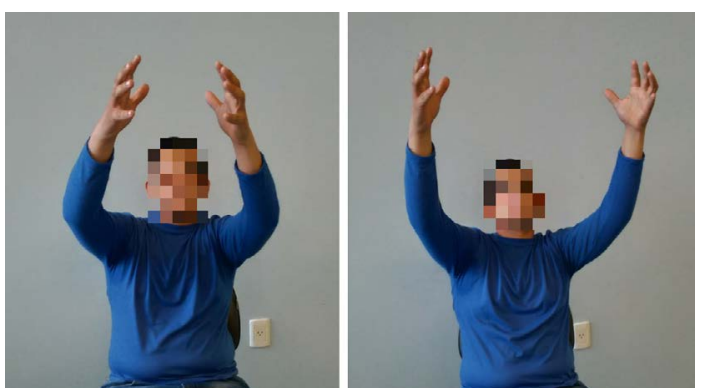

Source: Adapted from Stephens and Clement (2010, p. 8).

The student, commenting on a hypothetical situation in which gravity would cease to exist, gestures with his hands the movement of a book that would initially be at rest on a horizontal table. Therefore, the prediction of the behavior of the book is not only expressed verbally but together with a gesture describing the movement, which characterizes the evidence of a mental image used by the student to presuppose the movement of the book vertically.

Considering the methodological developments adopted by Stephens and Clement (2010), we emphasize the importance of depictive gestures to identify mental images and students' reasoning in solving problems and understanding concepts studied. This movement can reveal the implicit knowledge inherent in the internal visualization (mental stimulation) through the externalization by gestural analysis (HOSTETTER; ALIBALI, 2004; KRAUSS, 1998; SCHERR, 2008). Next section, we present three investigations, directed to the Teaching of Sciences, that used the depictive gestures as indicators for the analysis and study of the understanding of the concepts approached through didactic sequences composed by tools of hyper cultural mediation, characterized using computational software.

\section{The construction and utilization of methodological development}

The union of the Think Aloud adapted technique with depictive gestural analysis emerges as an important methodological link within the scope of qualitative research, within this universe of research, in which it is generally sought to identify the virtues of students' understanding of certain scientific concepts. With the intention to exemplify and show ways to use this proposal, we will present below the extensions of the analysis of the gestures obtained during the interviews conducted by the Report Aloud of three works engaged in teaching science.

One of the main directives of the report aloud technique is that we seek to identify the source of the mental image (or mental simulation) used by the student to solve the problem at hand. After identifying the mental image by observing the hand gesture, the researcher should ask details about the image and also the source of the image, where the student has seen this image for the first time. The source of the mental image can then be categorized as coming from a psychophysical, social, cultural or hypercultural mediation (SOUZA, 2004) if the researcher finds it appropriate. 


\section{The methodology applied to the Chemistry Teaching}

An example in the Chemistry Teaching of development and use of the methodological development proposed here is observed in the research carried out by Ramos (2015), who in her doctoral work, sought to understand how changes occur in students' cognitive structure after using a molecular modeling software, starting from the premise that the understanding of many chemical concepts is directly related to visuospatial abilities, since the visualization is part of a system of perception of symbols that are typical of this Science.

In his work, Ramos (2015) adopts Polanyi's (1958) epistemological framework in which knowledge is treated tactically as an implicit and inherent knowledge of each subject. As a result, the gestural analysis is performed to contemplate expressions not verbally explained by students, adding meanings to verbal discourse through the analysis of the depictive gestures identified during the interviews conducted by the Report Aloud method.

The research is based on Wagner, Nusbaum and Goldin-Meadow (2004) and Hegarty (2004) built on the premise that a depictive gesture performed at the moment the student is explaining his reasoning process to solve a problem may represent the externalization of a mental image or mental representation produced by the student to solve the problem. In this way, Ramos (2015) sought to catalog and link the gestures to a certain concept addressed, aiming to identify the theoretical aspects present in the reasoning developed in the resolution of the proposed problems.

In the analysis movement, one of the evaluated segments is related to the representations of simple and double chemical bonds. The gestures produced by the students when referring to chemical bonds were, as a rule, of a cultural nature since most of the gestures referred to the representation of toothpicks. One of the academics, labelled student L (Figure 4), gestured all the time when he talked about his depiction of chemical bonds, and his gestures indicated a profuse usage of the stick model.

We highlight an excerpt in which the student L comments on traces, even knowing that there are other important factors behind these representations

[Student L:] So, uh, if I say that after I took the course I felt compelled to use the software, let's just say oh, forget the trace and think about the cloud, it makes a sum on top of that. But no use, you're still clinging to the question of the sticks and balls model, but will replace the balls with another one, by the table representation. (RAMOS, 2015, p. 121, our translation).

Figure 3-Gestures produced by Student L to represent chemical bonds
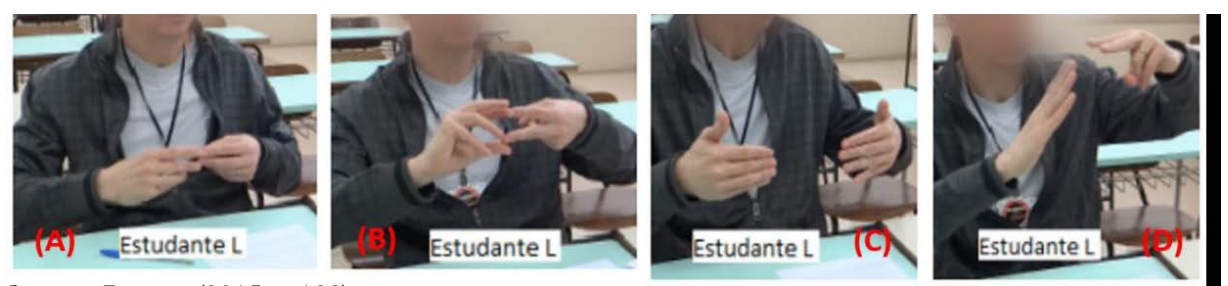

Source: Ramos (2015, p.122). 
In image (A), the student represented a double bond by "V" fingers; in (B), the double bond was represented with $V$-fingers and one atom by a shell-shaped hand; in $(C)$, the expert represented the double bond with the formation of a plane; in (D), the double connection with "V" fingers and adjacent connection with flat hand. During this interview, the student was being asked about his answer to a written test on molecular representation and stereoisomerism. Images A to D refer to the depictive gestures that correspond to the imagery produced by the student on the different representations of alkenes that he could imagine when answering questions on isomerism, such images include double bonding, an imaginary plane and nearby atoms connected to the central carbon.

We can also observe other examples of gestures produced for the explanations of the concepts of simple and double chemical bonds, also used in the analysis of the investigation.

Figure 4-Gestures representing chemical bonds
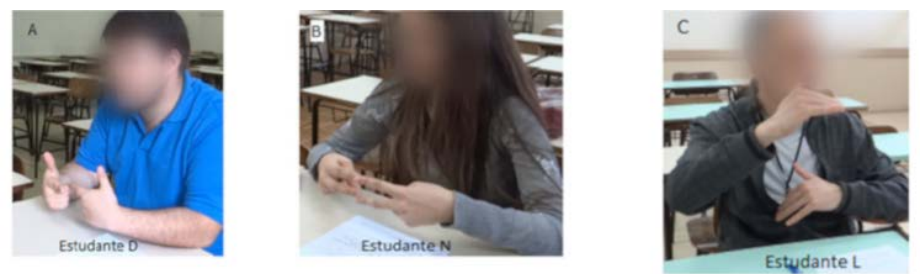

Source: Ramos (2015, p. 128).

In 4-A, we see student $\mathrm{D}$ representing a double bond, placing both index fingers in parallel. At 4-B, student $\mathrm{N}$ showed the double bond touching the index and the middle fingertips of both hands, also to explain the twist. Finally, student L in Figure 4-C showed the orbitals of the 'pi' bond, above and below the bond axis. During this part of the interview, students were being asked why a double bond wouldn't be able to rotate (regarding the concept of isomerism). Student D and $\mathrm{N}$ explained that the double bonding wouldn't be able to rotate because "it would break up the bonding" - in case of their gesture, disconnecting the fingers as it rotates. In the case of student L, he explained that he imagined the 'pi' orbitals of the double bonding preventing the rotation.

Another segment evaluated was related to the study of Conformational Analysis, involving the contents corresponding to the following topics: cis/trans conformations; single bond; double bond; intramolecular rotation; graph and polarity of the molecule that emerged throughout the activities. Next, we will present some gestures used in this segment of the analysis, identifying the connections with the understanding of the concepts addressed and revealed by the students. 
Figure 5 - Significant gestures on conformational analysis
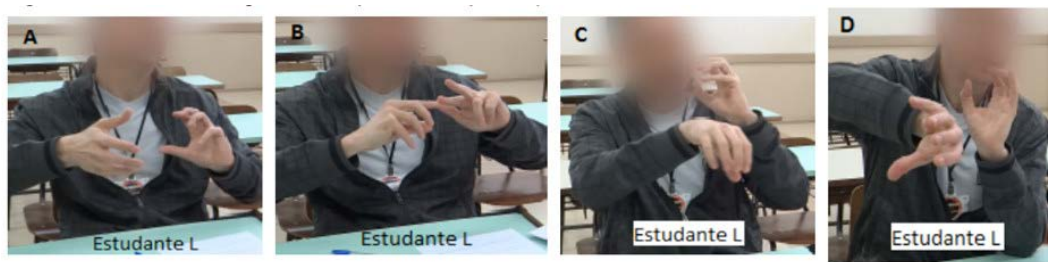

Source: Ramos (2015, p. 127).

The gestures represented by student $\mathrm{L}$ describe, together with his verbal discourse, the reasoning and his mental images accessed and used to answer the questions proposed by the researcher. In Figure 5-A, it shows an intramolecular rotation, the student rotates both hands, one clockwise and the other counter-clockwise, already in 5-B occurs the rupture of the connection 'pi', represented by the fingers in " $\mathrm{V}$ " of the left hand, Figures 5-C and 5-D represent the rotation of a Butane molecule in the conformational analysis, 5- $\mathrm{C}$ shows the transposition which was constructed from the turn of the hands starting from the cis position, by its $5-\mathrm{D}$ shows an intermediate position between cis and trans. In this part of the interview, the student $\mathrm{L}$ was explaining what was the first thing that came to his mind when trying to answer a question in the written test that required him to related two columns, the left column with 4 different conformations of $n$-butane with the right column with different positions in a molecular energy graph. The student explained why a specific intermediate molecular conformation had steric impairments that naturally set the molecular energy of such conformer higher than other (according to the student, it gets 'bad' for the molecule as there is little room between the atoms as the conformer rotates). During his explanation he produced a series of depictive gestures that were analysed. Similar gestures were also made by other students, as shown in the following image.

Figure 6 - Depictive gestures produced by students to represent the different conformers of a molecule
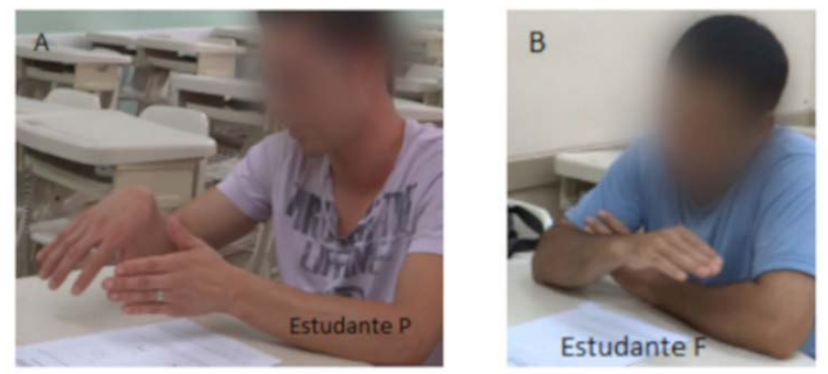

Source: Ramos (2015, p. 125).

In figure 6-A, student $\mathrm{P}$ showed with the right hand the presence of the substituents on the same side of the plane, marked by the flat left hand, composing the cis form; in 6-B, student $\mathrm{F}$ showed the plane that separates the two sides of a molecule and that is a condition to think of cis/trans conformation. 
Given this scenario, we believe that the depictive gestures carried out during the interview conducted by the report aloud actually refer to the mental images used by students to formulate the necessary answers to the proposed problems. In other words, the student imagines the situation by creating mental images and from these images builds up his answer, according to Monaghan and Clement (1999) the main indicative for this process is the depictive gesture that exposes hypotheses imagined by the student.

In the sequence, we will present the methodological development of gestural analysis in two works directed to Physics Teaching.

\section{The methodology applied to Physics Teaching}

The following investigations are conducted using the same methodology, making use of the report aloud technique to obtain both verbal discourse and depictive gestures, with the objective of uncovering possible changes in students' cognitive structures after activities with characterized hyper cultural mediations using the software in the form of virtual benches. The research conducted by Wolff (2015) opted for the teaching of mechanical collisions as the content of knowledge of physics teaching for undergraduate students, mostly engineering academics. The work carried out by Trevisan (2016) adopted the teaching of wave-particle duality, investigating its conceptual understanding by academics of the last period of the teacher training in Physics.

In the teaching of collisions, Wolff (2015) sought to didactically explore two situations of collisions through the Modellus 4.01 software used throughout the activities, a collision between a projectile abandoned at a certain height to the ground and a frontal collision between two projectiles both being or not initially moving. Within these two situations, several physical concepts can be explored, such as the principle of conservation of mechanical energy, analysis of linear momentum among other aspects. Therefore, the gestures that we present here were recorded during questioning directed to these two possibilities of mentioned collisions.

Figure 7 shows the gestures performed by the student when asked to explain her answer in the written test about the return height of a ball bouncing on the street and about it collides elastically to the floor; while in Figure 8 the she imagines the ball 'inside' the simulation.

Figure 7 - Gestures demonstrating the reduction of height when the student imagines the ball bouncing on the street

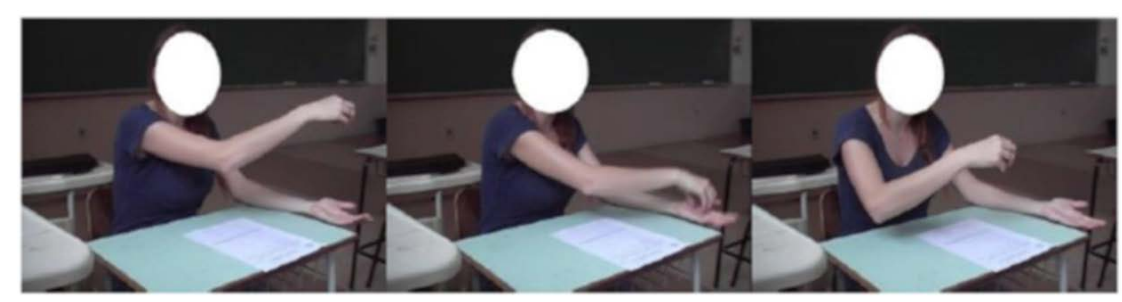

Source: Wolff (2015, p. 148). 
The sequence of gestures performed describes the collision of the ball to the ground and consequently its loss of height, so the student does not correctly describe the situation taken as an elastic collision, we separate an excerpt from the verbal language of the student in which she explains her reasoning during the sequence of gestures:

[Student:] [...] I think I can see the ball. It is I imagine a ball stinging in the street with a bow, the other bow, hitting the ground. Except that my ball in the street would lose its height (fig.7).

[Researcher:] Yes.

[Student:] Then I cannot put her out on the street without losing her height. There, I have to put her inside the computer so she does not lose height. [movement is shown in figure 8]

[Researcher:] You have to put it where?

[Student:] In the computer, in the program, in that simulation. Because my ball, in my real world, on the street, will lose height. (WOLFF, 2015, p. 148 , our translation).

Figure 8-Gestures indicating the return of the ball to the same pitch, situation imagined "inside" the simulation

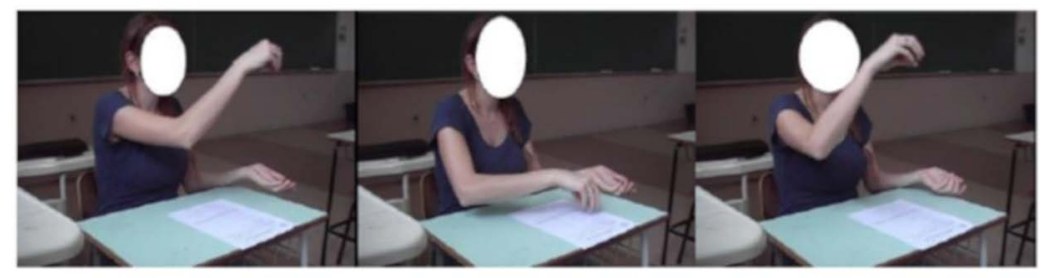

Source: Wolff (2015, p. 149).

Wolff (2015) has found that when the student mentally simulates using mental images related to everyday life, the gestures necessarily indicate height reduction (not representing an elastic collision). However, when using mental images constructed during the simulation, the gestures indicate the maintenance of the height after the collision, with the gestures performed together with the verbal language, they are concrete pieces of evidence of the reasoning adopted by the student, and their mental simulation linked to the activity of mediation via software, made it possible to recreate a situation beyond what is observed daily to reach a solution to the proposed problem.

Another example of a depictive gesture is shown in Figure 9. The student is led to write in his test that precedes the interview about what happens to two bodies after a collision, knowing that one was in motion and another at rest, both with the same mass, in which the student uses the movement of the hands to represent a frontal collision between a moving projectile and a body at rest. 
Figure 9-Gestures indicating an elastic collision between a moving projectile and a resting target


Source: Wolff (2015, p. 193).

In this situation, the student uses both hands to represent the movement of the target and the projectile before and after an elastic collision. The sequence of gestures is performed concomitantly to his verbal discourse during the report aloud, the student gesturally represents the transfer of linear momentum between the bodies of the system. The gestures reinforce the pieces of evidence of mental images used by the student because when representing the bodies in a collision with hands, he naturally explains his imagination.

The next example of research in which depictive gestural analysis was used is also inclined to physics teaching, seeking to verify students' understanding of the wave-particle duality to construct a sketch of the epistemological profile of each participant student in relation to this physical content.

The research is focused on private interpretations of each student about the behavior of the quantum object (photon and electron), for which activities were performed involving two software in the form of a virtual bench that represented the experimental arrangement of the double slit and the virtual interferometer of Mach-Zehnder. After doing out the activities based on structured scripts, the individual dialogues between the student and the researcher were done out following the report aloud method, the conversations were based on the understanding of the results obtained in the virtual experiments operating in a classical and quantum regime.

In this example, the student was led in his test to express and explain the behaviour of a photon in the experimental setup of the Mach-Zehnder Interferometer, when it operates in a quantum (monophotonic) regime. Therefore, in explaining the trajectory, as well as the behavior of just one photon, through the interferometer, from the emission source to the contact with the scintillating screen, the student imagines the photon being divided in two when confronting the first semi-reflecting mirror of the interferometer: "[...] here I imagined that the photon is emitted by the source and there is a device that separates, isn't it?, causes the photon to follow a path, divides the photon follows a path" (TREVISAN, 2016, p. 105, our translation) (Figure 10-I). Following the explanation of his reasoning, the student claims to imagine the second semi-reflecting mirror, joining the two photons arising from the interaction with the first semi-reflecting mirror. "Then it has two mirrors, isn't it?, it will be reflected and in the end, will go, the two, these two divisions will end up joining and will form the photon again". (TREVISAN, 2016, p. 105, our translation) (Figure10-II). 
Figure 10 - (I) Student using his hands to simulate the trajectory of the photon, which divides the path of the right and left; (II) Hands pointing to the same point, simulating the meeting of the parts (waves) of the photon

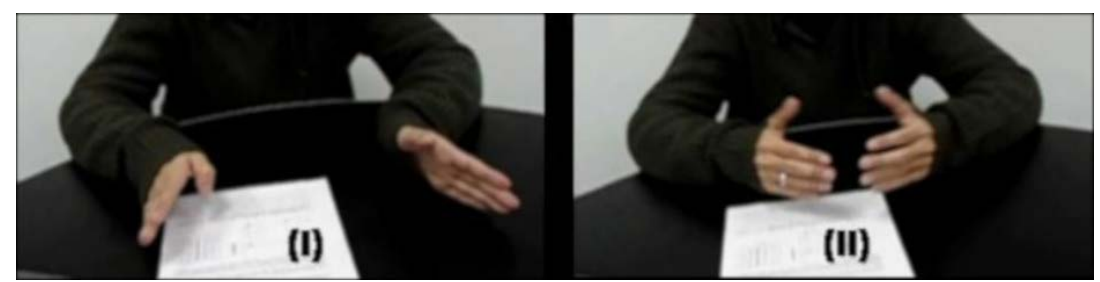

Source: Trevisan (2016, p. 105).

The gestures performed to reinforce the evidence of the mental images used throughout the reasoning, involuntarily, the student represents the imagined movement on the division of the photon to solve the proposed situation.

In another proposed situation/problem in the open and dissertation test and evidenced throughout the dialogue, the student is questioned about his conception about the electron (or a quantum object). In this respect, the student makes clear that his image in relation to the electron is the representation of a corpuscle (Fig. 11-I) derived from the atomic models presented in the books throughout his academic life, along with drawings made by teachers during the classes. In thinking of the electron with an associated wave, it is imagined a sinetype propagation but it is clear that it does not stop at a representation of a particle with a "tail" (Fig. 11-II), as it recalls a class in which his teacher emphasized the non-imagination of this representation.

[Student:] [...] the teacher puts a sketch on the picture that was a ball with his little legs with a tail behind, like a wave, this should not have. But the wave must be associated with it and why it makes the interference pattern" (TREVISAN, 2016, p. 114, our translation).

Figure 11 - (I) Both hands, representing a Sphere; (II) Indicator of the right hand in oscillatory movement, representing a sine wave

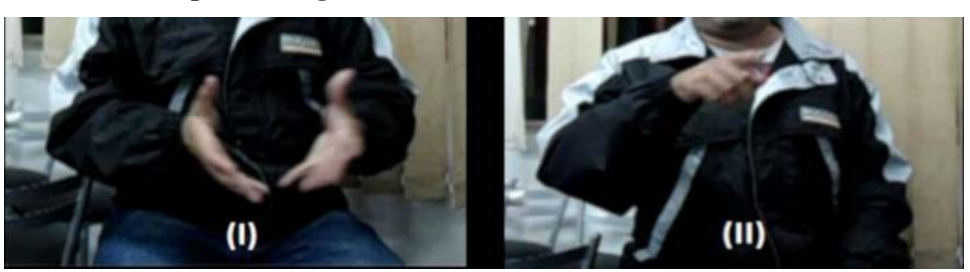

Source: Trevisan (2016, p. 114).

The relation of the gesture reinforces the image of the student, which in addition to externalizing such a conception verbally, he expresses it gesturally, according to Monaghan and 
Clement (1999) is real evidence of the mental simulation used by the student to understand and argue about the situation/problem.

Given this constructed panorama, we can assess the sustainability of the combined use of the report aloud technique with Depictive Gesture Analysis in the research in Science Teaching. The results observed in the aforementioned investigations are aimed to reinforce the qualitative analysis and can also reinforce the pieces of evidence in the students' understanding of a certain content obtained throughout the verbal discourse through the identification and analysis of the gestures performed. Next, figure 12 points out a synthesis with the primary segmentation for the development of Report Aloud as a particular technique of qualitative research.

Figure 12 - Summary of the methodological proposal: Report Aloud

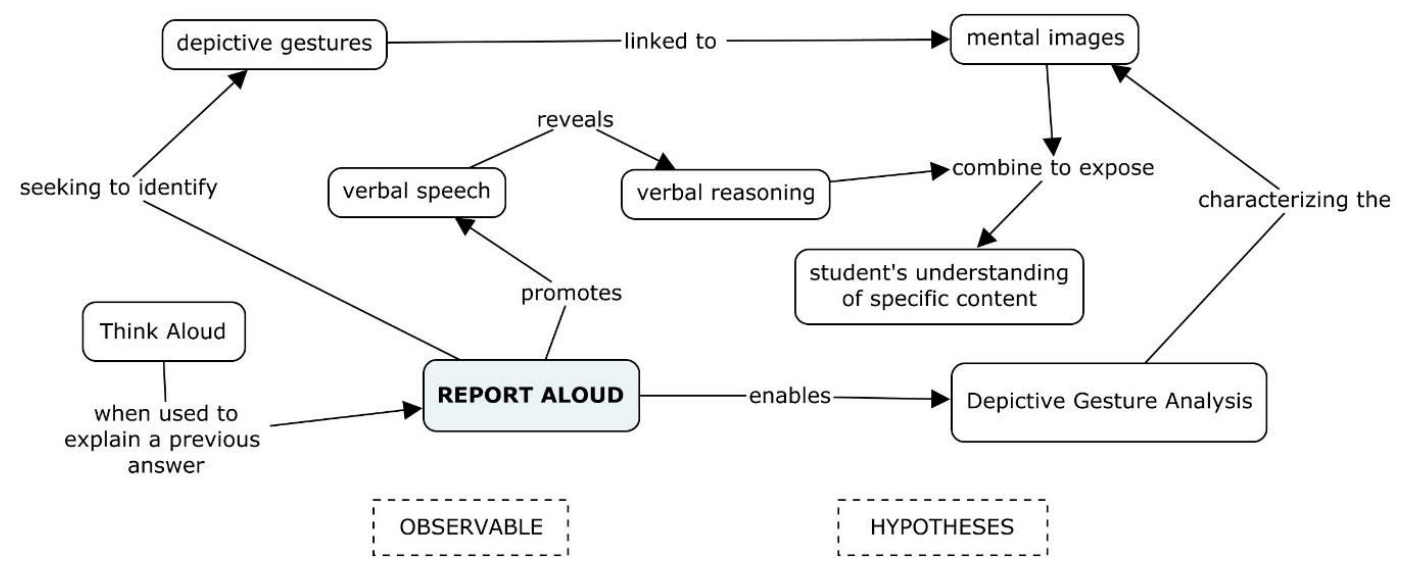

Source: Prepared by the authors.

In view of this, our methodological proposal takes as its primary focus the observable aspects of the investigation, ascending to the possible formulation of hypotheses that will justify the results obtained through all the research process. In papers that seek data production through dialogues, the report aloud technique allows the obtaining of information from a verbal and gestural language, making possible the analysis movement of the depictive gestures. The intertwining between verbal speech and imagery speech is clear in the analysis made in Figure 5 (chemistry) - in which the mental image correspondent of the double bonding gives support to the verbal speech, and Figure 8 (physics) - in which the mental image of the ball not returning to its original height contradicts the verbal speech of elastic collision.

We believe that this methodological proposal can add solid evidence regarding mental images and students' understanding of scientific knowledge, corroborate this conjecture by virtue of the results presented in the previously mentioned works inclined to Physics and Chemistry teaching.

In addition, the research we have mentioned shows ways and possibilities for establishing a link between students' mental images, raised with the help of Report Aloud and a 
theoretical-epistemological referential that aims an analysis of the emergence and foundation of recognized content with the course of certain studies. Ramos (2015), Wolff (2015) and Trevisan (2016) used the Cognitive Mediation Theory (CMT) (SOUZA, 2004) as a theoretical -epistemological contribution for the analysis of mental images obtained with the technique Report Aloud. The central concern of the authors was to verify which mediations were responsible for creating or modifying the mental images of the students about specific contents, that is, analysing which situations or artefacts were remembered by the students when they expressed their reasoning and consequently their mental images.

This is because TMC understands cognitive mediation as the connection of external structures, as auxiliary processing devices with internal mechanisms present in the intracerebral structure. In addition, this process will only be effectively useful to the individual if it has a way of interacting effectively, translating the entries, exits, and processing between them. When this process is taken into account, a view of human cognition arises as a sophisticated set of internal and external information processing mechanisms that together form a complex organized system.

This is an example within a universe with several potentialities for the connection of a qualitative method with a referential that supplies the demand of signification throughout the reading of the obtained data, thus intermingling theoretical-epistemological-philosophical aspects with the methodological delineation.

\section{Final considerations}

Our aim in writing this manuscript was to present a qualitative methodology for research in Science teaching. The proposed methodology is based fundamentally in the Report Aloud technique, guiding the conduction of interviews, in which the identification of static and/or dynamic mental images of the students can be performed by means of verbal cues from verbal and gestural language. Gestural language is analysed with the aid of depictive gestures analysis, inspired in the line of works by Monaghan and Clement (1999) and Stephens and Clement (2010).

We verified through the researches listed in this article the methodological harmonization between the analysis performed. That is, the moments of dialogue provided by the Report Aloud technique enable the student to verbally and gesturally externalize their understanding of specific scientific concepts. In multiple investigations in science teaching this externalized understanding is used in favour of the teacher, characterizing itself as a potentiating factor in the opportunity of planning and development of didactic situations, with the purpose of teaching such contents in the classroom. In addition, the gestural analysis allows extracting implicit pieces of evidence to the discourse of the student.

Through the descriptive gestures, we can infer images and mental simulations used by the student when instigated to solve and explain problem situations. In this way, the teacher in the classroom can reinforce or correct the images, seeking to improve the existing conceptions.

Given this horizon, because we believe that problem solving is not possible without the student being able to construct images and mental simulations, we believe that mental images can be meaningful for the understanding of the studied phenomena. They become the starting point, allowing the student to construct the dynamic view of the conceptual transformation along of his reasoning. Therefore, the methodology, made effective by the Report 
Aloud technique, can lead to the identification of acquired and/or modified knowledge during didactic mediations.

\section{Acknowledgments}

To the Coordenação de Aperfeiçoamento de Pessoal de Nível Superior (CAPES) for the support of this research grant.

\section{References}

ANDERSON, J. R. Arguments concerning representations for mental imagery.

Psychological Review, Washington, v. 85, n. 4, p. 249, 1978. DOI: https://doi. org/10.1037/0033-295X.85.4.249

EISENCK, M. W.; KEANE, M. T. Psicologia cognitiva: um manual introdutório. Porto Alegre: Artes Médicas, 1994.

HEGARTY, M. Mechanical reasoning by mental simulation. Trends in Cognitive Sciences, Kidlington, v. 8, n. 6, p. 280-285, 2004.

HOSTETTER, A.; ALIBALI, M. On the tip of the mind: gesture as a key to conceptualization. In: FORBUS, K. G.; GENTNER, D.; REGIER, T. (ed.). Proceedings of the 26th annual meeting of the Cognitive Science Society. Newark: Lawrence Erlbaum, 2004. p. 589-594. Disponível em: https://cloudfront.escholarship.org/dist/prd/content/ qt0bq3923m/qt0bq3923m.pdf?t=op32b6. Acesso em: 25 ago. 2017.

KRAUSS, R. M. "Why do we gesture when we speak?" Current Directions in Psychological Science, Thousand Oaks, v. 54, n. 7, p. 54-60, 1998.

MONAGHAN, J. M.; CLEMENT, J. J. Use of a computer simulation to develop mental simulations for understanding relative motion concepts. International Journal of Science Education, v. 21, n. 9, p. 921-944, 1999. DOI: https://doi.org/10.1080/095006999290237.

MOREIRA, M. A. Modelos mentais. Investigações em Ensino de Ciências, Porto Alegre, v. 1, n. 3, p. 193-232, 1996.

MOREIRA, M. A. Pesquisa básica em educação em ciências: uma visão pessoal. Revista Chilena de Educación Científica, Santiago de Chile, v. 3, n. 1, p. 10-17, 2004.

NARDI, R. Memórias do ensino de ciências no Brasil: a constituição da área segundo pesquisadores brasileiros, origens e avanços da pós-graduação. Revista do Imea Unila, Foz do Iguaçu, v. 2, n. 2, p. 13-46, 2014.

NARDI, R.; ALMEIDA, M. J. P. M. Formação da área de ensino de ciências: memórias de pesquisadores no Brasil. Revista Brasileira de Pesquisa em Educação em Ciências, Belo Horizonte, v. 4, n. 1, p. 90-100, 2004.

NARDI, R.; ALMEIDA, M. J. P. M. Investigação em ensino de ciências no Brasil segundo pesquisadores da área: alguns fatores que lhe deram origem. Pro-Posições, Campinas, v. 18, n. 1, p. 213-226, 2007. 
OTERO, M. R. El uso de imágenes en la educación em ciencias como campo de investigación. Revista de Enseñanza de la Física, Córdoba, Argentina, v. 17, n. 1, p. 9-22, 2004.

POLANYI, M. Personal knowledge: towards a post-critical philosophy. Chicago: The University of Chicago Press, 1958.

RAMOS, A. F. Estudo da influência da utilização de software de modelagem molecular no processo de aprendizagem de conceitos químicos por estudantes do ensino médio e superior. 2015. 230 f. Tese (Doutorado em Ensino de Ciências e Matemática) - Universidade Luterana do Brasil, Canoas, 2015.

SCHERR, R. E. Gesture analysis for physics education researchers. Physical Review Special Topics: physics education research, College Park, v. 4, n.1, p. 10101/1-10101/9, 2008.

SOUZA, B. C. A teoria da mediação cognitiva: os impactos cognitivos da hipercultura e da mediação digital. 2004. 282 f. Tese (Doutorado em Psicologia) - Universidade Federal de Pernambuco, Recife, 2004.

STEPHENS, A. L.; CLEMENT, J. J. Documenting the use of expert scientific reasoning processes by high school physics students. Physical Review Special Topics: physics education research, College Park, v. 6, n. 2, p. 20122/1-20122/15, 2010. DOI: https://doi. org/10.1103/PhysRevSTPER.6.020122.

TREVISAN, R. Um estudo da relação entre as imagens mentais utilizadas por estudantes de mecânica quântica e seu perfil epistemológico: uma investigação pela metodologia Report Aloud. 2016. 169 f. Dissertação (Mestrado em Ensino de Ciências e Matemática) - Universidade Luterana do Brasil, Canoas, 2016.

VAN-SOMEREN, M. W.; BARNARD, Y. F.; SANDBERG, J. A. C. The think aloud method: a practical guide to modeling cognitive processes. London: Academic Press, 1994.

WAGNER, S. M.; NUSBAUM, H.; GOLDIN-MEADOW, S. Probing the mental representation of gesture: is handwaving spatial? Journal of Memory and Language, Maryland Heights, v. 50, n. 4, p. 395-407, 2004.

WOLFF, J. F. S. Qual a mudança na estrutura cognitiva de estudantes após o uso de simulações computacionais?: uma investigação da relação entre representações computacionais internalizadas e aprendizagem significativa de conceitos no campo das colisões mecânicas em física. 2015. 260 f. Tese (Doutorado em Ensino de Ciências e Matemática) - Universidade Luterana do Brasil, Canoas, 2015.

Submetido em 06/11/2017. Aceito em 04/02/2019

Contact: Universidade Luterana do Brasil, Programa de Pós-

Graduação em Ensino de Ciências e Matemática, Av. Farroupilha, 8001, São José, Canoas, 92425-900, RS, Brasil. 